\title{
PERENCANAAN DAN PERANCANGAN LANSKAP TAMAN MAJU BERSAMA HAJI SAIBUN DI KELURAHAN JATI PADANG, JAKARTA SELATAN
}

\author{
(Landscape Planning and Design of Taman Maju Bersama Haji Saibun in Jati Padang, \\ South Jakarta) \\ Moh. Sanjiva Refi Hasibuan ${ }^{1}$, Ray March Syahadat ${ }^{1}$, Lasmaria Sidabutar $^{2}$ \\ ${ }^{1}$ Program Studi Arsitektur Lanskap, Institut Sains dan Teknologi Nasional \\ ${ }^{2}$ Member of Indonesian Landscape Architect Association DKI Jakarta \\ E-mail: refi.arl@istn.ac.id
}

Diterima 21 Januari 2020, Disetujui 9 April 2020

\begin{abstract}
ABSTRAK
Taman Maju Bersama (TMB) merupakan program pemerintah Provinsi DKI Jakarta dalam menyediakan Ruang Terbuka Hijau (RTH) dengan menggunakan pendekatan perencanaan yang berbasis masyarakat (bottom-up). Artikel ini bertujuan untuk menghasilkan desain taman yang fungsional dan estetis melalui proses yang kreatif, dengan tetap memperhatikan karakteristik tapak serta berlandaskan partisipasi masyarakat (community participation). Proses perencanaan dan perancangan TMB Haji Saibun di Jakarta Selatan ini melalui beberapa tahapan mulai dari kegiatan survei lapangan (site survey), Focus Group Discussion (FGD), analisis tapak, penyusunan program dan konsep, dan proses perancangan. Kegiatan FGD dilakukan dalam 3 tahap, yaitu pertama pada tahap awal perencanaan guna menampung aspirasi dan kebutuhan masyarakat terhadap taman, kedua guna mendapatkan masukan dari masyarakat terhadap hasil desain taman yang telah dibuat, dan ketiga untuk mensosialisasikan hasil desain akhir taman yang akan dilaksanakan nantinya. Desain TMB Haji Saibun menerapkan konsep umum Taman Betawi (Betawi Park) untuk mengangkat karakter lokal kawasan dan konsep khusus yaitu desain taman untuk berbagai tingkatan usia. Ruang-ruang taman dibagi menjadi 4 ruang utama yang akan mengakomodasi kebutuhan masyarakat dari usia anak-anak, remaja, dewasa, dan orang tua atau lansia.
\end{abstract}

Kata Kunci: desain, perancangan, perencanaan, Ruang Terbuka Hijau, Taman Maju Bersama.

\begin{abstract}
Taman Maju Bersama (TMB) is a program of DKI Jakarta Provincial Government in providing Green Open Space using community based planning approach (bottom-up). The aim of this article was to created functional as well as aesthetic garden design by creativity process, and focusing the site charectiristics through community participattion. The planning and design process of TMB Haji Saibun in South Jakarta goes through several stages starting from field survey activities, Focus Group Discussion (FGD), site analysis, programming and concept, and design process. FGD carried out in three stages, firstly in the early stages of planning to accommodate the community aspirations and needs for the park, secondly in order to get input from the community on the result of the design that has been made, and thirdly to socialize the final design of the park to be implemented later. The design of TMB Haji Saibun applies the general concept of Betawi Park to raise the local character of the region, and the specific concept of park design for various age levels. Park spaces area divided into 4 (four) main spaces that will accommodate the needs of community from children, adults, parents or the elderly.
\end{abstract}

Keywords: design, planning, Green Open Space, Taman Maju Bersama. 


\section{PENDAHULUAN}

Sejak 20 tahun terakhir, Provinsi DKI Jakarta sebagai ibukota negara telah mengalami perubahan yang signifikan dalam hal tata guna lahan. Jumlah penduduk yang semakin meningkat merupakan salah satu faktor penting yang memicu terjadinya perubahan penggunaan lahan. Bahkan berdasarkan data Badan Pusat Statistik (BPS) menyatakan bahwa jumlah penduduk DKI Jakarta pada tahun 2035 diproyeksikan mencapai angka 11 juta jiwa. Peningkatan jumlah penduduk ini seiring dengan peningkatan angka kebutuhan terhadap lapangan kerja dan tempat tinggal. Lahan yang terbatas mengakibatkan banyak terjadi penyalahgunaan fungsi lahan. Sehingga saat ini DKI Jakarta menjadi kekurangan Ruang Terbuka Hijau (RTH), daerah resapan air, danau/situ, waduk, dan sebagainya. Beberapa isu lingkungan dan sosial pun terus meningkat di dalam kehidupan masyarakat kota. Bencana banjir yang selalu terjadi setiap tahunnya, krisis air bersih, polusi, hingga masalah kesehatan dan tawuran antar warga kerap terjadi. Salah satu solusi yang dapat dilakukan untuk mengatasi permasalahan ini yaitu dengan cara menambah jumlah RTH publik.

Menyikapi hal ini, pemerintah Provinsi DKI Jakarta mencanangkan Kegiatan Strategis Dasar (KSD) guna meningkatkan kualitas dan kuantitas RTH di ibukota. Program Taman Maju Bersama (TMB) merupakan inovasi pemerintah DKI Jakarta dalam menyediakan ruang publik yang nyaman, aman, dan berkelanjutan, setelah sukses menyelenggarakan Ruang Terbuka Publik Ramah Anak (RPTRA). TMB merupakan konsep RTH yang menggunakan pendekatan "bottom up" yaitu melibatkan partisipatif masyarakat baik dalam perencanaan, pemanfaatan, dan pengelolaannya. Menurut Makhmudi (2018), partisipasi masyarakat diperlukan dalam suatu program pembangunan karena dapat menjadi kunci keberhasilan program pembangunan tersebut. Adapun bentuk-bentuk partisipasi yang dapat diberikan oleh masyarakat antara lain berupa buah pikiran, tenaga, dan barang atau harta benda. Diharapkan dengan adanya keterlibatan masyarakat secara langsung dapat menjadikan taman sebagai RTH publik yang berkelanjutan (sustainable). TMB sendiri memiliki fungsi antara lain menjadi ruang interaksi, rekreasi, dan kreasi bagi warga kota.

Salah satu tapak yang ditetapkan sebagai TMB yaitu berlokasi di Gang Haji Saibun. RT.002, RW.09, Kelurahan Jati Padang, Kecamatan Pasar Minggu, Jakarta Selatan. Lokasi ini memiliki potensi berupa luas area sebesar $1.813,3 \mathrm{~m}^{2}$. Lokasi tapak yang terhimpit oleh padatnya penduduk membuat kebutuhan akan taman sebagai ruang sosial sangat dibutuhkan oleh masyarakat. Sejauh ini di utara tapak sudah ada Ruang
Publik Terpadu Ramah Anak (RPTRA) Seruni namun masih dianggap belum cukup untuk mengakomodasi kebutuhan masyarakat setempat. Hal ini sejalan dengan hasil beberapa kajian mengenai RPTRA seperti yang dilaporkan Putra et al. (2018) serta Permanasari dan Lientino (2018) yang menyatakan bahwa RPTRA yang tersedia di Jakarta saat ini masih memiliki banyak permasalahan dan keberhasilannya diukur oleh keberagaman pengguna, tingkat aksesibilitas, dan tingkat aktivitas. Meskipun demikian, keberadaan RPTRA yang ada saat ini memiliki dampak positif bagi masyarakat (Sutanto dan Junadi, 2018; Prakoso dan Dewi, 2018a ; Prakoso dan Dewi, 2018b; Utami et al., 2016; Purnama, 2017; Supriyanto et al., 2017; Rosyidin et al., 2017).

Melihat dari fenomena di atas, perlu adanya kegiatan perencanaan dan perancangan TMB agar dapat menyelesaikan permasalahan kebutuhan ruang publik yang berkontestasi dari keinginan pemerintah yang diintepretasikan oleh keinginan dan kebutuhan masyarakat. Adapun tujuan dari perencanaan dan perancangan ini adalah menghasilkan desain taman yang fungsional dan estetis melalui proses yang kreatif dengan tetap memperhatikan karakteristik tapak serta berlandaskan partisipasi masyarakat.

\section{METODE}

Kegiatan perencanaan dan perancangan Taman Maju Bersama (TMB) ini berlokasi di Gang Haji Saibun (Gambar 1). Adapun waktu kegiatan yaitu selama 4 bulan mulai dari bulan Juni hingga September 2019.

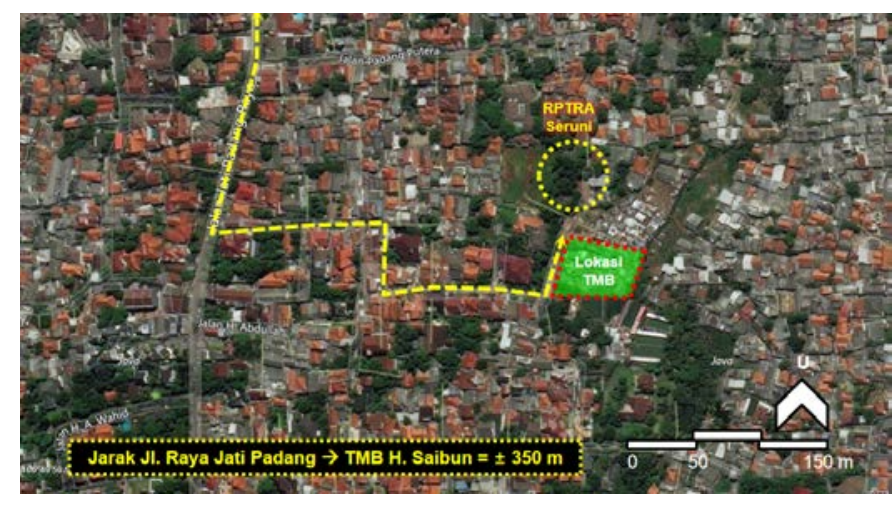

Gambar 1. Lokasi TMB Haji Saibun

Kegiatan perencanaan dan perancangan Taman Maju Bersama (TMB) ini menggunakan metode perencanaan dan perancangan Gold (1980) dengan pendekatan partisipasi masyarakat. Proses perencanaan dan perancangan meliputi tahap persiapan, inventarisasi, analisis dan sintesis, perencanaan dan perancangan. 
Pengambilan data dilakukan melalui survei tapak dengan melakukan pengukuran, pengamatan dan inventarisasi secara langsung. Data kebutuhan masyarakat diperoleh melalui kegiatan Focus Group Discussion (FGD) yang dilakukan sebanyak 3 kali. FGD pertama dilakukan untuk pemetaan sosial guna mendapatkan profil kawasan. FGD kedua dilakukan setelah menghasilkan desain awal (basic design) yang didiskusikan bersama warga guna mendapatkan masukan dan saran. Kemudian FGD ketiga dilakukan untuk sosialisasi desain akhir (final design). Tahapan perencanaan dan perancangan dapat dilihat pada Gambar 2.

Kegiatan FGD sering digunakan sebagai pendekatan kualitatif untuk memperoleh pemahaman mendalam tentang isu-isu sosial (Nyumba, et al. 2018). Program taman lingkungan sebaiknya ditentukan berdasarkan analisis kebutuhan pengguna dari berbagai tingkatan usia yang tinggal dalam radius $500 \mathrm{~m}$ (Prakoso dan Dewi, 2018c). Berdasarkan hasil FGD 1 yang dihadiri oleh 30 orang peserta yang terdiri atas ketua RT.002 dan RW.09, perwakilan warga dari tokoh pemuda, lbu PKK, Komunitas, perwakilan dari Kecamatan Pasar Minggu, perwakilan dari Kelurahan Jati Padang, dan tim teknis Bidang Jalur Hijau Dinas Pertamanan dan Hutan Kota DKI Jakarta, serta dipandu oleh seorang sosiolog.

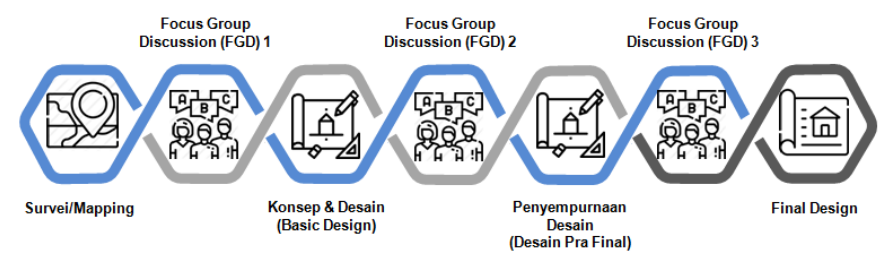

Gambar 2. Tahapan Perencanaan dan Perancangan TMB

Adapun batasan perencanaan dan perancangan Taman Maju Bersama Haji Saibun ini adalah sampai dengan tahap pra-final pembuatan gambar rancangan tapak (siteplan draft).

\section{Kondisi Umum}

Taman Maju Bersama (TMB) Haji Saibun berlokasi di Gang Haji Saibun, RT.002 RW.09 Kelurahan Jati Padang, Kecamatan Pasar Minggu, Kota Jakarta Selatan. Tapak berada di tengah permukiman penduduk serta hanya berjarak sekitar $350 \mathrm{~m}$ dari jalan raya Jati Padang dan 2,5 km dari jalan raya Pasar Minggu. Tapak memiliki luas 1.813,3 $\mathrm{m}^{2}$ dengan status hak kepemilikan oleh Dinas Pertamanan dan Hutan Kota Provinsi DKI Jakarta. Adapun batas-batas tapak adalah sebagai berikut:
Sebelah Utara

Sebelah Timur

Sebelah Selatan

Sebelah Barat : Jalan gang Haji Saibun dan

RPTRA Seruni dan tempat penampungan barang bekas Permukiman dan tempat penampungan barang bekas

Permukiman dan tempat penampungan barang bekas permukiman

Secara umum, kondisi tapak berupa hamparan rumput liar dan terdapat beberapa pohon kecil dan besar. Kondisi topografi tapak bergelombang dan memiliki area dengan kemiringan lahan yang sedikit agak curam pada sisi tapak bagian selatan. Gambaran topografi tapak dapat dilihat pada Gambar 3.

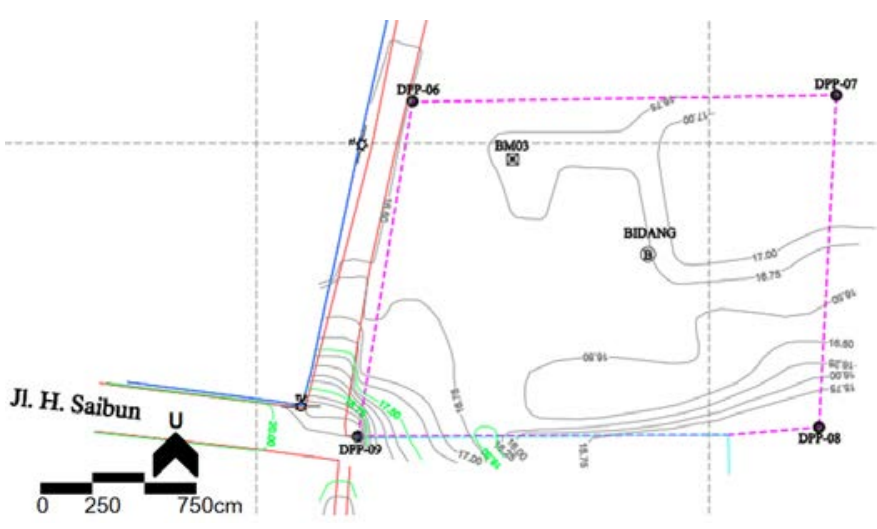

Gambar 3. Topografi Tapak

\section{HASIL DAN PEMBAHASAN}

\section{Konsep Umum}

Masyarakat yang tinggal di sekitar tapak mayoritas merupakan masyarakat keturunan Betawi yang saat ini sudah berbaur dengan masyarakat dari berbagai daerah di luar Jakarta. Daerah Jakarta Selatan termasuk kawasan yang dikenal masih memiliki kekentalan budaya Betawi yang cukup kuat hingga saat ini. Guna melestarikan budaya lokal dan memperkuat karakter kawasan maka konsep umum perancangan yang diangkat adalah konsep Taman Betawi (Betawi Park). Konsep ini diadopsi dari pembagian zona perkampungan betawi tempo dulu yang terbagi menjadi 3 (tiga) yaitu Betawi Tengah (Urban), Betawi Pinggir/Betawi Orak/Betawi Udik (Rural), dan Betawi Pesisir (Windarsih, 2013). Secara geografis dan karater fisik tapak, maka TMB Haji Saibun dapat dikategorikan masuk ke dalam zona Betawi Tengah dan Betawi Pinggir. Adapun karakter lanskap kawasan budaya Betawi Tengah (Urban) dan Betawi Pinggir (Rural) berdasarkan Forum Pengkajian dan Pengembangan Perkampungan Budaya Betawi (FORJIBANG) tahun 2016 adalah sebagai berikut: 
1. Kondisi kontur bergelombang hingga berbukit

2. Jenis tanaman/vegetasi merupakan peralihan dari Betawi Pesisir

3. Terdapat tanaman hias langka dan tanaman obat Betawi

4. Memiliki hewan khas seperti burung alap-alap, Sapi perah, kambing, burung gelatik, ayam, unggas air, dan Ikan.

5. Memiliki blandongan yaitu bangunan tanpa dinding seperti pendopo atau gazebo

6. Terdapat lapangan terbuka untuk kegiatan seni budaya atau acara masyarakat.

Konsep dan karakter kawasan tersebut akan diadopsi ke dalam konsep desain baik pada elemen hardscape maupun softscape. Konsep tersebut juga disesuaikan dengan kebutuhan aktivitas dan fasilitas masyarakat berdasarkan hasil FGD dengan masyarakat setempat.

\section{Focus Group Discussion}

Berdasarkan hasil FGD, diperoleh diperoleh beberapa informasi terkait permasalahan yang terjadi dan dirasakan oleh masyarakat di lingkungan mereka, bentuk-bentuk kegiatan dan jenis-jenis fasilitas taman yang dibutuhkan, serta pendapat dan masukan terkait kegiatan pengelolaan taman (Tabel 1 ).

Tabel 1. Permasalahan, Kebutuhan Aktivitas dan Fasilitas

\section{PERMASALAHAN}

1. Tidak adanya panggung/podium untuk kegiatan/acara warga

2. Kurangnya sarana bermain untuk anak-anak

3. Warga perlu area untuk berinteraksi

4. Remaja banyak yang suka nongkrong

5. Remaja sekarang banyak yang asyik bermain gadget

6. Tempat penampungan barang bekas di sebelah tapak cukup mengganggu secara visual

7. Banjir di dalam tapak ketika hujan besar

8. Perlu pembatas/pagar taman

\section{KEBUTUHAN AKTIVITAS}

1. Olahraga pagi, senam lansia, senam ibu-ibu

2. Olahraga voli dan badminton

3. Pencak silat dan marawis

4. Jogging/lari pagi

5. Kegiatan PKK

6. Bercocok tanam/apotek hidup

7. Refleksi

8. Pertunjukan seni budaya

\section{KEBUTUHAN FASILITAS}

1. Pagar taman

2. Saluran drainase taman

3. Parkir motor/sepeda

4. Panggung serbaguna untuk pertunjukan dan senam

5. Jogging track

6. Jalur refleksi

7. Bangku taman dan gazebo

8. Ramp untuk disabilitas
9. Kolam ikan

10. Pos jaga dan lampu taman

11.Toilet umum

FGD 1 juga menghasilkan beberapa masukan terkait kegiatan pengelolaan taman yaitu, untuk pengelolaan fisik taman seperti keamanan taman, kegiatan pemotongan rumput, dan pemeliharaan taman lainnya menjadi tanggung jawab Dinas Pertamanan dan Hutan Kota DKI Jakarta dengan melibatkan masyarakat setempat sebagai tenaga kerjanya. Sementara untuk pengelolaan kegiatan diserahkan sepenuhnya kepada masyarakat seperti kelompok PKK, Karang Taruna, dan Komunitas yang ada di kelurahan Jati Padang.

Kegiatan FGD ke-2 dilakukan setelah dihasilkan konsep desain TMB. Konsep desain ini disajikan dalam bentuk produk (output) antara lain konsep umum, konsep ruang, konsep vegetasi, konsep sirkulasi, siteplan draft, dan gambar ilustrasi suasana dalam bentuk 3 dimensi (3D). Konsep ini dirangkum dalam sebuah file data dalam bentuk cetak dan file PowerPoint kemudian dipresentasikan dalam kegiatan FGD 2 yang juga dihadiri oleh perwakilan warga, tokoh masyarakat, perwakilan Kelurahan dan Kecamatan, serta tim dari Dinas Pertamanan dan Hutan Kota DKI Jakarta. Setelah kegiatan pemaparan konsep oleh konsultan perencana, dilanjutkan dengan sesi diskusi dipandu oleh seorang Sosiolog. Warga terlibat aktif dan antusias memberikan dan menyampaikan masukan terkait konsep baik secara lisan maupun tertulis. Warga diminta menuliskan komentar dan masukannya pada setiap gambar yang sudah dicetak pada kertas ukuran A3. Hasil diskusi dan berbagai masukan dari warga ini akan menjadi pertimbangan dalam perbaikan konsep dan desain TMB Haji Saibun. Dokumentasi kegiatan FGD 2 dapat dilihat pada Gambar 4.

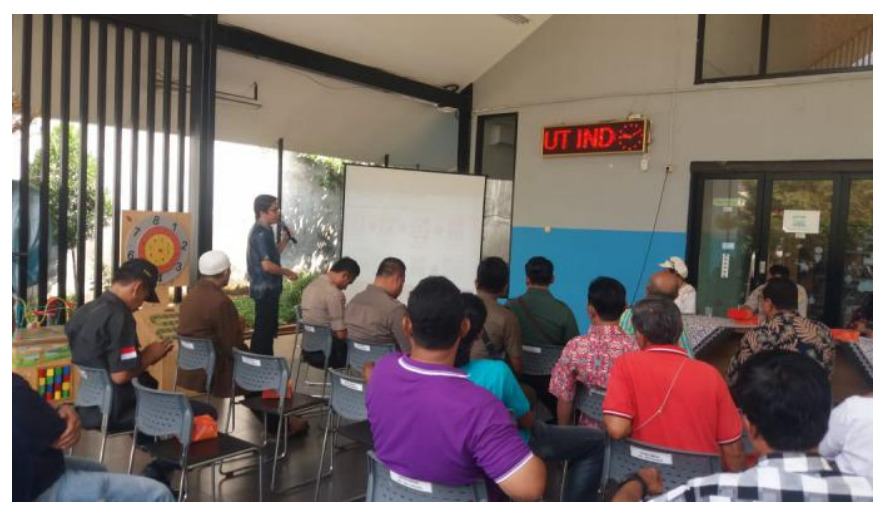

Gambar 4. Kegiatan Focus Group Discussion (FGD)

Tahap berikutnya setelah memperbaiki dan menyempurnakan konsep serta desain berdasarkan hasil FGD 2 adalah melakukan kegiatan FGD ke-3. Pada kegiatan FGD 3 disampaikan hasil desain final yang 
sudah diasistensikan dan disetujui terlebih dahulu oleh tim dari Dinas Pertamanan dan Hutan Kota DKI Jakarta dalam hal ini yaitu tim teknis Bidang Jalur Hijau. Kegiatan FGD 3 lebih bersifat sosialisasi hasil desain akhir kepada warga. Pada FGD 3 ini juga dihadiri oleh perwakilan warga, pihak Kelurahan Jati Padang, dan Kecamatan Pasar Minggu. Desain akhir TMB ini disampaikan secara lisan melalui presentasi dan dilanjutkan dengan sesi tanya jawab antara warga dengan konsultan perencana. Melalui kegiatan FGD 3 ini diharapkan masyarakat mengetahui dan dapat ikut menyosialisasikan hasil desain TMB ini kepada masyarakat lain sebelum tahap berikutnya gambar desain digunakan untuk keperluan lelang (tender).

\section{Analisis Tapak}

Analisis tapak terhadap data inventarisasi dan identifikasi TMB Haji Saibun disajikan secara deskriptif (Tabel 2). Data biofisik dan sosial hasil pengamatan dan FGD1 dianalisis guna memahami lebih dalam mengenai kondisi tapak dan mengidentifikasi potensi yang dapat dioptimalkan serta permasalahan yang harus diatasi pada tapak.

Tabel 2. Analisis Tapak

\begin{tabular}{|c|c|c|c|c|}
\hline \multirow{2}{*}{\multicolumn{2}{|c|}{ Data }} & \multicolumn{2}{|c|}{ Analisis } & \multirow{2}{*}{ Sintesis } \\
\hline & & Potensi & Kendala & \\
\hline A. & $\begin{array}{l}\text { Data } \\
\text { Biofisik }\end{array}$ & & & \\
\hline 1. & $\begin{array}{l}\text { Lokasi } \\
\text { dan } \\
\text { Aksesibili } \\
\text { tas }\end{array}$ & $\begin{array}{l}\text { - Lokasi } \\
\text { taman } \\
\text { dekat } \\
\text { dengan } \\
\text { RPTRA } \\
\text { Seruni } \\
\text { - Lokasi } \\
\text { hanya } \\
\text { berjarak } \\
\text { sekitar } 300 \\
\text { m dari } \\
\text { jalan Raya } \\
\text { utama Jati } \\
\text { Padang } \\
\text { - Terdapat } \\
\text { di } \\
\text { tengah-ten } \\
\text { gah } \\
\text { permukim } \\
\text { an }\end{array}$ & $\begin{array}{l}\text { - Sirkulasi } \\
\text { yang cukup } \\
\text { sempit } \\
\text { menuju } \\
\text { lokasi } \\
\text { hanya } \\
\text { dapat } \\
\text { dilalui } 1 \\
\text { mobil } \\
\text { - Terdapat } \\
\text { banyak } \\
\text { sirkulasi } \\
\text { (gang) } \\
\text { sempit } \\
\text { untuk } \\
\text { mencapai } \\
\text { lokasi } \\
\text { taman }\end{array}$ & $\begin{array}{l}\text { - Perlu signage } \\
\text { yang jelas } \\
\text { sebagai } \\
\text { penanda dan } \\
\text { pengarah } \\
\text { menuju lokasi } \\
\text { Taman Maju } \\
\text { Bersama Haji } \\
\text { Saibun }\end{array}$ \\
\hline 2. & $\begin{array}{l}\text { Tata } \\
\text { Guna } \\
\text { Lahan } \\
\text { dan } \\
\text { Landcov } \\
\text { er }\end{array}$ & $\begin{array}{l}\text { - Tapak } \\
\text { merupaka } \\
\mathrm{n} \\
\text { lahan/area } \\
\text { terbuka } \\
\text { yang } \\
\text { berada di } \\
\text { tengah-ten } \\
\text { gah } \\
\text { permukim } \\
\text { an } \\
\text { - Tapak } \\
\text { hanya } \\
\text { berupa } \\
\text { groundcov } \\
\text { er, } \\
\text { beberapa } \\
\end{array}$ & $\begin{array}{l}\text { - Area di } \\
\text { sekitar } \\
\text { tapak } \\
\text { merupakan } \\
\text { tempat } \\
\text { aktivitas } \\
\text { penampung } \\
\text { an barang } \\
\text { bekas/rong } \\
\text { sokan }\end{array}$ & $\begin{array}{l}\text { - Diperlukan } \\
\text { konsep } \\
\text { penataan } \\
\text { vegetasi guna } \\
\text { menghalangi } \\
\text { view ke arah } \\
\text { sekitar tapak } \\
\text { - Vegetasi } \\
\text { eksisting yang } \\
\text { berupa } \\
\text { pohon-pohon } \\
\text { kecil dapat } \\
\text { dipertahankan } \\
\text { atau } \\
\text { dipindahkan } \\
\text { sementara } \\
\text { pohon besar } \\
\end{array}$ \\
\hline
\end{tabular}

\begin{tabular}{|c|c|c|c|}
\hline \multirow{2}{*}{ Data } & \multicolumn{2}{|c|}{ Analisis } & \multirow{2}{*}{ Sintesis } \\
\hline & Potensi & Kendala & \\
\hline & $\begin{array}{l}\text { pohon, } \\
\text { dan sedikit } \\
\text { pohon } \\
\text { besar }\end{array}$ & & $\begin{array}{l}\text { harus } \\
\text { dipertahankan di } \\
\text { dalam } \\
\text { perencanaan }\end{array}$ \\
\hline 3. Topografi & $\begin{array}{l}\text { - Sebagian } \\
\text { besar area } \\
\text { tapak } \\
\text { berkontur } \\
\text { relatif } \\
\text { datar }\end{array}$ & $\begin{array}{l}\text { - Secara } \\
\text { makro, } \\
\text { tapak } \\
\text { berada } \\
\text { pada area } \\
\text { yang paling } \\
\text { rendah dari } \\
\text { area } \\
\text { sekitarnya } \\
\text { - Level } \\
\text { topografi } \\
\text { permukaan } \\
\text { tapak } \\
\text { berada di } \\
\text { bawah } \\
\text { permukaan } \\
\text { jalan } \\
\text { sehingga } \\
\text { sering } \\
\text { tergenang } \\
\text { ketika } \\
\text { musim } \\
\text { hujan } \\
\end{array}$ & $\begin{array}{l}\text { - Tapak harus } \\
\text { diurug/timbun } \\
\text { dengan tanah } \\
\text { minimal setara } \\
\text { dengan level } \\
\text { permukaan jalan } \\
\text { - Perlu penataan } \\
\text { drainase yang } \\
\text { baik agar air } \\
\text { limpasan hujan } \\
\text { tidak tergenang } \\
\text { di dalam tapak }\end{array}$ \\
\hline 4. Hidrologi & $\begin{array}{l}\text { - Terdapat } \\
\text { kali kecil di } \\
\text { sisi Timur } \\
\text { tapak }\end{array}$ & $\begin{array}{l}\text { - Belum } \\
\text { terdapatnya } \\
\text { saluran } \\
\text { drainase } \\
\text { yang baik } \\
\text { pada tapak } \\
\text { dan } \\
\text { sekitarnya } \\
\text { sehingga } \\
\text { sering } \\
\text { menimbulk } \\
\text { an masalah } \\
\text { genangan } \\
\text { air saat } \\
\text { musim } \\
\text { hujan } \\
\text { - Tapak } \\
\text { merupakan } \\
\text { area yang } \\
\text { lebih } \\
\text { rendah } \\
\text { daripada } \\
\text { area } \\
\text { sekitarnya } \\
\text { sehingga } \\
\text { aliran } \\
\text { drainase di } \\
\text { sekitarnya } \\
\text { akan } \\
\text { melalui/me } \\
\text { nuju tapak }\end{array}$ & $\begin{array}{l}\text { - Pembuatan } \\
\text { saluran drainase } \\
\text { dari tapak } \\
\text { menuju Kali ke } \\
\text { arah Timur guna } \\
\text { mengalirkan air } \\
\text { dari permukiman } \\
\text { dan sekitar } \\
\text { taman } \\
\text { - Pengadaan } \\
\text { sumber air (kran } \\
\text { air) untuk } \\
\text { menunjang } \\
\text { aktifitas } \\
\text { pengguna taman } \\
\text { (sesuai hasil } \\
\text { FGD1) }\end{array}$ \\
\hline 5. Vegetasi & $\begin{array}{l}\text { - Terdapat } \\
\text { beberapa } \\
\text { pohon } \\
\text { eksisting } \\
\text { jenis } \\
\text { mahoni } \\
\text { yang bisa } \\
\text { dimanfaatk } \\
\text { an dalam } \\
\text { perancang } \\
\text { an taman } \\
\text { - Terdapat } \\
\text { 2-3 pohon } \\
\text { besar } \\
\text { yang } \\
\text { harus } \\
\text { dipertahan }\end{array}$ & $\begin{array}{l}\text { - Jenis } \\
\text { vegetasi } \\
\text { eksisting di } \\
\text { dalam } \\
\text { tapak } \\
\text { masih } \\
\text { sedikit dan } \\
\text { kurang } \\
\text { beragam }\end{array}$ & $\begin{array}{l}\text { - Perlu } \\
\text { penggunaan } \\
\text { jenis vegetasi } \\
\text { yang sesuai } \\
\text { dengan kondisi } \\
\text { lahan dan } \\
\text { karakteristik } \\
\text { kawasan } \\
\text { - Penggunaan } \\
\text { tanaman } \\
\text { screening guna } \\
\text { menutupi } \\
\text { badview sekitar } \\
\text { tapak }\end{array}$ \\
\hline
\end{tabular}




\begin{tabular}{|c|c|c|c|c|}
\hline \multirow{2}{*}{\multicolumn{2}{|c|}{ Data }} & \multicolumn{2}{|c|}{ Analisis } & \multirow{2}{*}{ Sintesis } \\
\hline & & Potensi & Kendala & \\
\hline & & $\begin{array}{l}\text { kan } \\
\text { didalam } \\
\text { desain } \\
\text { karena } \\
\text { kondisinya } \\
\text { masih baik }\end{array}$ & & \\
\hline & Visual & $\bullet$ & $\begin{array}{l}\text { - Tidak } \\
\text { terdapat } \\
\text { goodview di } \\
\text { dalam } \\
\text { tapak } \\
\text { maupun di } \\
\text { sekitar } \\
\text { tapak } \\
\text { - Pada arah } \\
\text { Utara, } \\
\text { Timur, } \\
\text { Selatan } \\
\text { merupakan } \\
\text { badview } \\
\text { yaitu } \\
\text { pemandang } \\
\text { an tempat } \\
\text { penampung } \\
\text { an barang } \\
\text { bekas yang } \\
\text { terlihat dari } \\
\text { dalam } \\
\text { tapak }\end{array}$ & $\begin{array}{l}\text { - Penggunaan } \\
\text { elemen lanskap } \\
\text { yang dapat } \\
\text { menciptakan } \\
\text { goodview di } \\
\text { dalam tapak } \\
\text { - Mengurangi } \\
\text { badview yang } \\
\text { terlihat dari } \\
\text { dalam tapak ke } \\
\text { area sekitar } \\
\text { dengan } \\
\text { screening } \\
\text { tanaman } \\
\text { maupun } \\
\text { hardscape }\end{array}$ \\
\hline B. & $\begin{array}{l}\text { Data } \\
\text { Sosial }\end{array}$ & & & \\
\hline & $\begin{array}{l}\text { Kependu } \\
\text { dukan }\end{array}$ & $\begin{array}{l}\text { - Masyaraka } \\
\text { t peduli, } \\
\text { aktif, dan } \\
\text { antusias } \\
\text { dengan } \\
\text { rencana } \\
\text { pembangu } \\
\text { nan } \\
\text { Taman } \\
\text { Maju } \\
\text { Bersama } \\
\text { Haji } \\
\text { Saibun } \\
\text { - Lokasi } \\
\text { taman } \\
\text { berada di } \\
\text { tengah-ten } \\
\text { gah } \\
\text { masyaraka } \\
\text { t } 3 \text { gang, } \\
\text { yaitu gang } \\
\text { Saibun, } \\
\text { Karang } \\
\text { Pola, dan } \\
\text { gang } \\
\text { Masjid. } \\
\text { - Area } \\
\text { sekitar } \\
\text { taman } \\
\text { banyak } \\
\text { terdapat } \\
\text { anak-anak } \\
\text { dan lansia } \\
\text { - Area } \\
\text { sekitar } \\
\text { taman } \\
\text { memiliki } \\
\text { karang } \\
\text { taruna dan } \\
\text { komunitas } \\
\text { yang aktif }\end{array}$ & $\begin{array}{l}\text { - Kebiasaan } \\
\text { masyarakat } \\
\text { yang } \\
\text { kadang } \\
\text { membuang } \\
\text { sampah ke } \\
\text { dalam } \\
\text { tapak } \\
\text { - Remaja-re } \\
\text { maja yang } \\
\text { suka } \\
\text { nongkrong } \\
\text { di dalam } \\
\text { tapak pada } \\
\text { sore hari }\end{array}$ & $\begin{array}{l}\text { - Masyarakat } \\
\text { dapat dilibatkan } \\
\text { dalam } \\
\text { pengelolaan } \\
\text { taman } \\
\text { - Komunitas-komu } \\
\text { nitas yang aktif } \\
\text { dapat } \\
\text { diberdayakan } \\
\text { untuk menyusun } \\
\text { program } \\
\text { pemanfaatan } \\
\text { taman } \\
\text { - Diperlukan } \\
\text { penjaga taman } \\
\text { (security) dan } \\
\text { penerangan } \\
\text { taman yang baik } \\
\text { untuk mencegah } \\
\text { tindakan asusila } \\
\text { maupun } \\
\text { vandalisme }\end{array}$ \\
\hline
\end{tabular}

\section{Konsep Ruang}

Pembagian ruang pada tapak dibagi berdasarkan kebutuhan aktivitas dan fasilitas serta mempertimbangkan permasalahan yang terjadi di lingkungan masyarakat. Menurut Prakoso dan Dewi (2018), program ruang yang ada di taman lingkungan perlu mengakomodasi kebutuhan berbagai kelompok usia demikian juga dengan penataan ruangnya. Aderina et al. (2018) dalam hasil penelitiannya melaporkan bahwa kelompok usia memiliki pengaruh signifikan terhadap perilaku pengguna ruang publik daripada gender, sehingga diperlukan adanya pembagian ruang serta fasilitas yang dapat mengakomodasi kegiatan antar golongan usia. Pembagian berdasarkan golongan usia ini juga nantinya akan menyesuaikan dengan fasilitas yang dibutuhkan.

Dalam perencanaan dan perencanaan TMB Haji Saibun ini, guna membentuk pola keterhubungan antar ruang maka ruang-ruang pada tapak dibagi berdasarkan tingkatan usia atau strata kehidupan dalam sebuah keluarga yaitu mulai dari anak-anak, remaja, dewasa, dan orang Tua. Tingkatan ini membentuk 4 (empat) ruang utama di dalam tapak dan dihubungkan oleh ruang-ruang pendukung lainnya. Konsep pembagian ruang pada tapak dapat dilihat pada Gambar 5 .

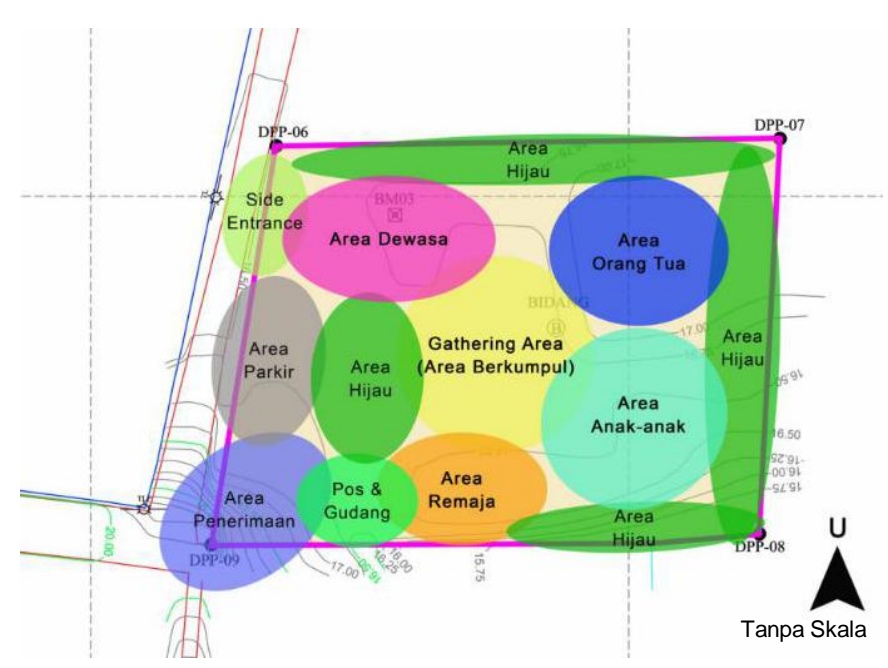

Gambar 5. Konsep Ruang

Pada gambar di atas dapat dilihat bahwa area penerimaan sebagai pintu utama taman berada di sisi Barat Daya tapak. Pintu ini menjadi akses masuk bagi pejalan kaki dan sepeda motor maupun sepeda. Sementara pintu samping berada di sisi Barat Laut tapak yang hanya dapat dilewati oleh pejalan kaki. Berdekatan dengan area penerimaan, disediakan area parkir dan pos jaga taman yang sekaligus berfungsi sebagai gudang penyimpanan peralatan taman. Pada bagian dalam taman merupakan pembagian ruang-ruang utama yang terdiri atas area anak-anak, remaja, dewasa, dan 
orang tua. Pada bagian tengah sebagai pusat (center) menjadi ruang bersama untuk aktivitas berkumpul dan kegiatan yang bersifat massal. Area anak-anak berada di sisi Timur tapak yang berdekatan dengan area orang tua agar pengawasan terhadap anak-anak tetap bisa dilakukan oleh para orang tua. Sementara area remaja dan dewasa diletakkan agak di depan pada sisi Barat berdekatan dengan pos jaga dan side entrance. Area hijau merupakan ruang yang berada di sepanjang pinggir tapak yang akan ditanami dengan vegetasi pembatas dan screen untuk menutupi badview yang ada di sekitar tapak.

\section{Konsep Vegetasi}

Taman Maju Bersama Haji Saibun dirancang dengan konsep vegetasi yang menyesuaikan karakter kawasan dan konsep umum yang diusung yaitu Betawi. Jenis-jenis tanaman yang digunakan diambil dari daftar jenis tanaman langka berdasarkan SK Gubernur No. 2359 Tahun 1987. Jenis ini kemudian diseleksi sesuai dengan fungsi dan ketersediaannya di lapangan. Selain tanaman langka tersebut, jenis tanaman yang akan digunakan juga dikombinasikan dengan tanaman hias dan obat yang banyak digunakan di perkampungan Betawi mulai dari jenis tanaman semak hingga pohon besar. Pendekatan seleksi vegetasi ini juga pernah dilakukan oleh Wardiningsih et al., (2017) dalam merencanakan tata hijau di Setu Mangga Bolong. Adapun jenis tanaman yang digunakan untuk TMB Haji Saibun tertera pada Tabel 3.

Tabel 3. Konsep Vegetasi

\begin{tabular}{|r|l|l|l|}
\hline No. & Nama Lokal & \multicolumn{1}{|c|}{ Nama Latin } & Keterangan \\
\hline 1 & $\begin{array}{l}\text { Belimbing } \\
\text { Wuluh }\end{array}$ & Averhoa bilimbii & Pohon \\
\hline 2 & Gandaria & Buoea macrophylla & Tan. Langka \\
\hline 3 & Sawo Duren & Crysophyllum cainito & Pohon \\
\hline 4 & Cempaka Putih & Michelia alba & Pohon \\
\hline 5 & Kweni & Mangifera odorata & Tan. Langka \\
\hline 6 & Jambu Bol & $\begin{array}{l}\text { Syzygium } \\
\text { malaccensis }\end{array}$ & Tan. Langka \\
\hline 7 & Mahoni & Swietenia mahogani & Pohon \\
\hline 8 & Bisbul & Diospyros hilipensis & Tan. Langka \\
\hline 9 & Kucai & Ophiopogon jaburan & Groundcover \\
\hline 10 & Puring & Codiaeum varigatum & Semak \\
\hline 11 & Hanjuang & Cordyline herbstii & Semak \\
\hline 12 & Pisang Hias & Calathea lutea & Semak \\
\hline 13 & Bunga Tasbih & Canna sp. & Semak \\
\hline 14 & Mangkokan & Polyscias scutellaria & Semak \\
\hline 15 & Suji & Dracaena fragrans & Semak \\
\hline 16 & Kumis Kucing & Orthosiphon aristatus & Semak \\
\hline 17 & Gandarusa & Gandarusa vulgaris & Semak \\
\hline 18 & Sente & Alocasia sp. & Semak \\
\hline
\end{tabular}

Berdasarkan fungsinya, konsep vegetasi dibagi menjadi vegetasi peneduh, pembatas/screen, pengarah, dan estetik/focal point (Gambar 6). Vegetasi peneduh terdiri atas jenis pohon besar dengan tajuk lebar sementara vegetasi pembatas menggunakan kombinasi pohon dan semak tinggi guna menghalangi badview di sekitar tapak. Vegetasi pengarah menggunakan jenis pohon pendek dan semak sedang. Sedangkan untuk tanaman estetik sebagai focal point dipilih jenis pohon langka dan semak yang memiliki bunga atau warna daun yang menarik.

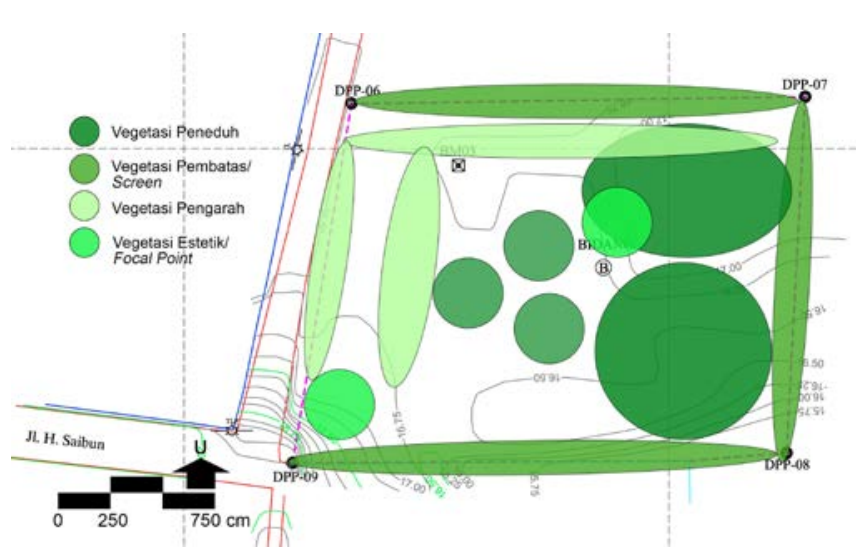

Gambar 6. Konsep Vegetasi

\section{Konsep Sirkulasi}

Konsep sirkulasi yang digunakan pada taman ini adalah kombinasi pola sirkulasi melingkar (round) dan lurus/langsung (linear). Pola melingkar memberikan kemudahan akses bagi pengguna untuk menjangkau seluruh bagian taman serta sekaligus berfungsi sebagai jalur jogging track. Sementara pola lurus memberikan axis yang tegas menuju sebuah focal point di dalam taman serta menciptakan sekuen alur sirkulasi bagi pengguna taman (Gambar 7). Sekuen-sekuen pada jalur sirkulasi ditentukan oleh tata letak elemen-elemen taman sehingga kecepatan pergerakan pengguna dapat dikontrol. Perpaduan antara kecepatan gerak dan sifat pergerakan terhadap suatu objek akan menghasilkan suatu rasa emosional tertentu (Hakim, 2003). Adapun lebar jalur sirkulasi perlu mengakomodasi minimal kebutuhan dua orang dewasa berjalan bersisian. Selain itu jalur sirkulasi juga perlu dirancang dan mempertimbangkan kebutuhan untuk anak/orang berkebutuhan khusus (Prakoso dan Dewi, 2018).

Konsep sirkulasi pada TMB ini juga dirancang sesuai dengan prinsip umum perencanaan fasilitas pejalan kaki antara lain yaitu memenuhi aspek kontinuitas, keselamatan, keamanan, kenyamanan, dan aksesibilitas. Prinsip aksesibilitas yang dimaksud adalah setiap fasilitas yang direncanakan di dalam taman harus dapat diakses oleh seluruh pengguna, termasuk oleh pengguna dengan berbagai keterbatasan fisik (Kementerian PUPR, 2018). 


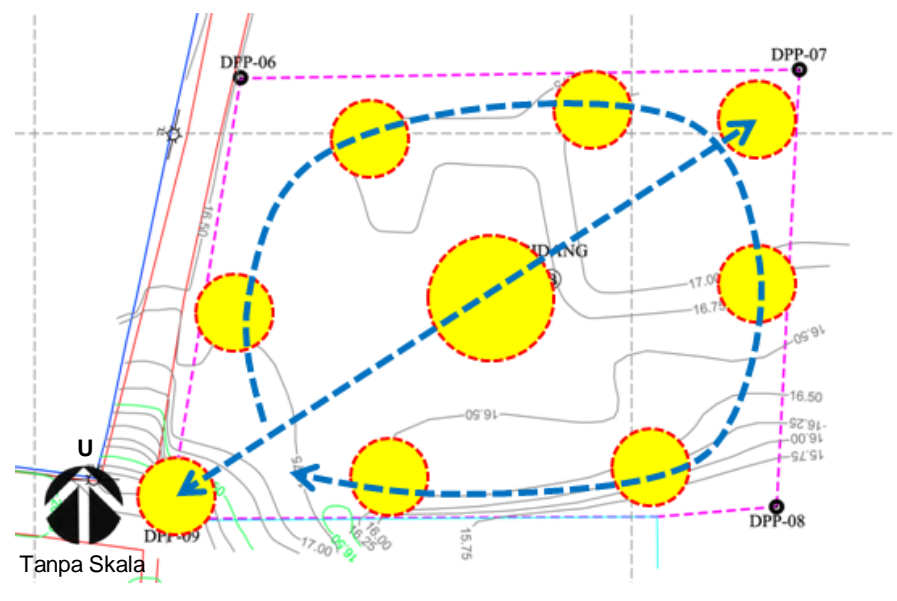

Gambar 7. Konsep Sirkulasi

\section{Siteplan}

Perencanaan dan perancangan lanskap TMB Haji Saibun menghasilkan gambar denah atau rencana tapak (siteplan) seperti pada Gambar 8. Pada gambar rencana tapak menunjukkan TMB Haji Saibun memiliki pintu masuk utama (main entrance) pada sisi Barat Daya tapak dan pintu masuk samping (side entrance) berada pada sisi Barat Laut tapak. Desain taman menyediakan area parkir khusus sepeda motor dan sepeda. Pada area penerimaan terdapat plaza dan pos jaga serta sirkulasi utama yang mengarahkan pengunjung menuju ke dalam taman. Pembagian ruang berdasarkan tingkatan usia menghasilkan beberapa fasilitas yang dibutuhkan oleh pengguna taman antara lain sebagai berikut:

\section{a. Area Anak-anak}

Pada area ini fungsi tapak difokuskan mengakomodasi kebutuhan anak-anak dalam bermain dan berinteraksi. Fasilitas yang disediakan antara lain alat permainan anak (playground set) yang terdiri atas playhouse, panjat jaring, ayunan, dan kolam ikan. Area ini terdiri dari hamparan rumput (lawn) dan rubber floor untuk menjaga kenyamanan dan keamanan anak-anak dalam bermain. Selain itu juga disediakan beberapa bangku taman yang berfungsi sebagai tempat duduk dan beristirahat bagi orang tua yang menemani anak-anaknya bermain. Area anak-anak ini memiliki persentase luasan yang lebih besar dibandingkan area lainnya.

\section{b. Area Remaja}

Area ini berada dekat dengan ruang penerimaan dan pos jaga agar segala kegiatan pengguna dapat terawasi dengan mudah khususnya oleh petugas penjaga taman. Pada area ini disediakan fasilitas yaitu area free wifi dan charging spot. Area ini berupa bangku taman memanjang yang mampu menampung banyak pengguna serta dilengkapi dengan meja dan colokan listrik sehingga para pengguna dapat menikmati fasilitas free wifi dengan nyaman menggunakan gawai. Selain itu, pada area ini juga disediakan fasilitas hammock dan dinding mural guna mengakomodasi kegiatan pengguna remaja yang bersifat lebih aktif.

\section{c. Area Dewasa}

Pada area ini disediakan fasilitas taman berupa viewing deck atau skywalk dengan tinggi \pm 3 m yang dapat digunakan untuk menikmati pemandangan taman dari atas dan berswafoto. Viewing deck ini didesain sedemikian rupa agar tetap aman bagi pengguna. Pada area ini juga terdapat area gazebo dengan desain menggunakan ornamen khas Betawi sebagai ruang berinteraksi antar pengguna taman.

\section{d. Area Orang Tua/Lansia}

Area ini berada pada axis jalur sirkulasi utama dimana sesuai kebutuhan pengguna dari tingkat usia orang tua maka disediakan fasilitas seperti gazebo Betawi sebagai tempat beristirahat menikmati taman serta berinteraksi. Selain itu juga disediakan sebuah jalur refleksi lengkap dengan railing dan bangku untuk beristirahat. Di sekitar area gazebo dibuat area flower bed yang terdiri dari beberapa tanaman berbunga menarik guna memberikan kesan dan suasana rileks bagi pengguna di area ini.

Selain area-area tersebut di atas, terdapat sebuah panggung serbaguna pada bagian tengah taman yang berfungsi sebagai area bersama atau berkumpul (gathering area). Panggung ini dapat dimanfaatkan oleh masyarakat untuk berbagai bentuk kegiatan seperti pertunjukan seni budaya, pencak silat, senam, dan sebagainya. Sementara untuk jalur sirkulasi didesain dengan lebar $150 \mathrm{~cm}$ agar dapat dilalui oleh 2 orang secara bersamaan dan pada beberapa titik disediakan ramp agar taman ini dapat dinikmati juga oleh kaum disabilitas. Jalur sirkulasi pada taman ini juga didesain dengan pola melingkar (circle) yang berfungsi sebagai jalur jogging (jogging track). Fasilitas atau elemen hardscape lainnya yang terdapat pada taman ini yaitu toilet umum yang terdiri atas toilet pria, wanita, dan toilet disabilitas. Kemudian signage berupa nama taman sebagai identitas dan pendukung estetika pada area penerimaan dibuat sesuai dengan nama yang disepakati bersama oleh masyarakat pada saat FGD 2 yaitu "Taman SAMASKA". Nama SAMASKA sendiri merupakan singkatan dari SAibun - MASjid - KArang Pola yang merupakan nama 3 (tiga) "gang" atau jalan kecil yang dapat digunakan untuk mencapai lokasi TMB Haji Saibun ini. 


\section{KETERANGAN}

1. Pintu Masuk Utama

2. Area Parkir Motor

3. Pos Jaga Taman

4. Gudang Peralatan

5. Panggung Serbaguna

6. Bangku-bangku Taman

7. Plaza

8. Playground Set

9. Panjat Jaring

10. Ayunan

11. Lapangan Rumput (Lawn)

12. Kolam Ikan Hias

13. Jogging Track

14. Hammock

15. Area Free Wifi \& Charge

16. Gazebo

17. Viewing Deck

18. Gazebo

19. Jalur Refleksi

20. Flower Bed

21. Pergola

22. Toilet Umum

23. Koridor Bambu

24. Pintu Masuk Samping

(Side Entrance)

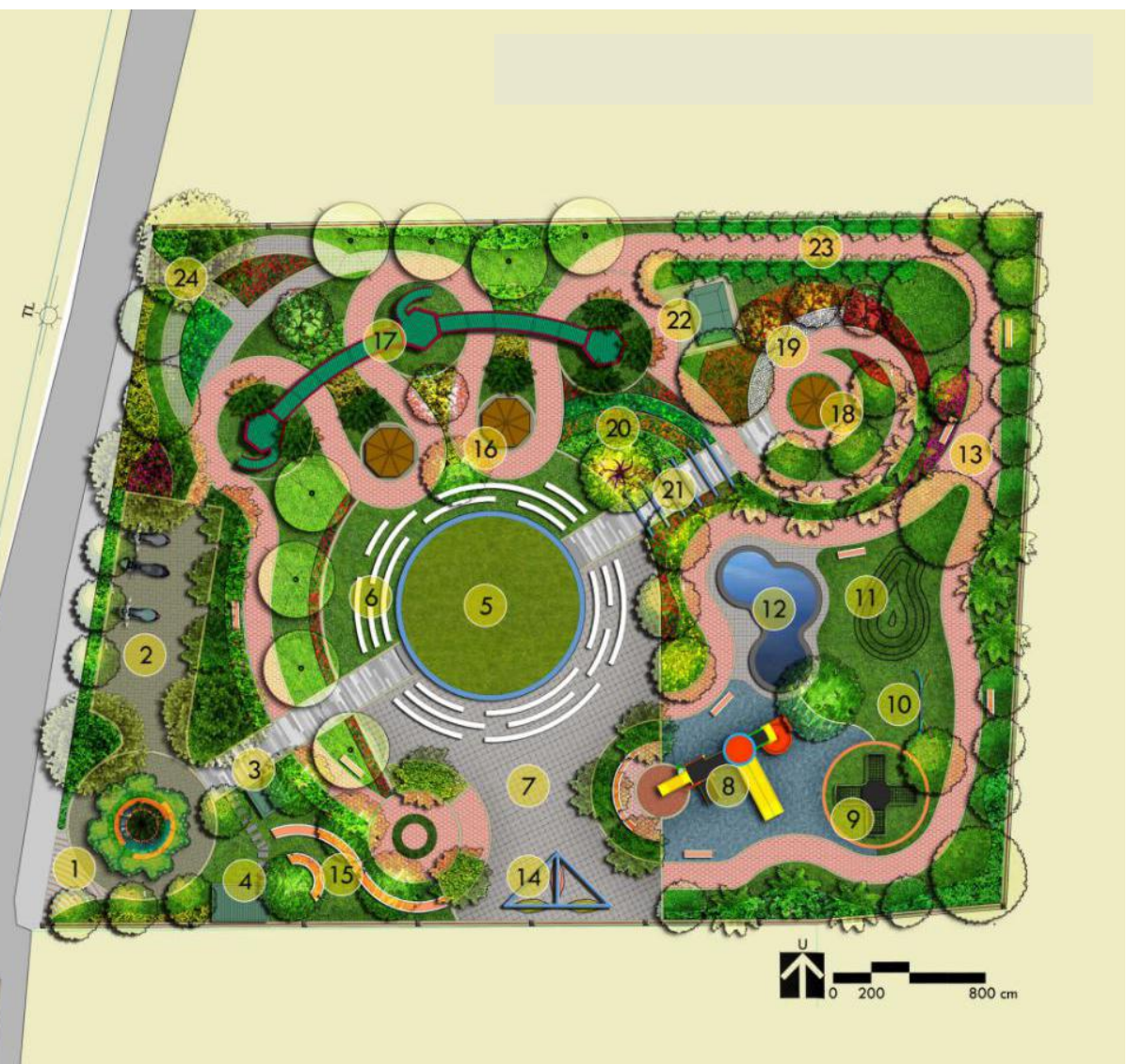

Gambar 8. Rencana Tapak (Siteplan)

\section{KESIMPULAN}

TMB Haji Saibun berdasarkan hasil FGD memiliki 8 permasalahan, 8 kebutuhan aktivitas, dan 11 kebutuhan aktivitas. Konsep perancangan yang diangkat yaitu Betawi Park yang diadopsi dari pembagian zona perkampungan betawi tempo dulu yang terbagi atas Betawi Tengah, Betawi Pinggir/Betawi Orak/Betawi Udik, dan Betawi Pesisir. Ruang pada TMB Haji Saibun dibagi menjadi berdasarkan tingkat usia pengguna yaitu area anak-anak, remaja, dewasa, dan lansia. Vegetasi penyusun yang akan digunakan menggunakan 18 vegetasi khas Betawi. Nama TMB yang disepakati oleh masyarakat yaitu Taman SAMASKA yang merupakan singkatan dari tiga gang untuk mencapai TMB, yakni Gang Saibun, Gang Masjid, dan Gang Karang Pola.

\section{REFERENSI}

Aderina, L., Syahadat, R.M., \& Putra, P.T. (2018). Perilaku Pengguna Ruang Publik di Kompleks Militer Batalyon Artileri Medan 10 Bogor. Tesa Arsitektur, 16(1): 1-10.

Gold, S. M. (1980). Recreation Planning and Design. McGraw-Hill Company. New York.

Hakim, R. \& Utomo, H. (2003). Komponen Perancangan Arsitektur Lansekap: Prinsip, Unsur, dan Aplikasi Desain. Bumi Aksara, Jakarta.
Kementerian PUPR. (2018). Pedoman Bahan Konstruksi Bangunan dan Rekayasa Sipil: Perencanaan Teknis Fasilitas Pejalan Kaki.

Makhmudi, D. P., \& Muktiali, M. (2018). Partisipasi Masyarakat dalam Pembangunan Prasarana Lingkungan pada Program Penataan Lingkungan Permukiman Berbasis Komunitas (PLPBK) di Kelurahan Tambakrejo, Kota Semarang. Jurnal Pengembangan Kota, 6(2): 108-117. DOI: 10.14710/jpk.6.2.108-117.

Nyumba, T.O., Wilson K, Derrick C.J. \& Mukherjee N. (2018). The Use of Focus Group Discussion Methodology: Insights from Two Decades of Application in Conservation. Methods in Ecology and Evolution, 9(1): 20-32. DOI: 10.1111/2041-210X.12860.

Permanasari, E. \& Lientino T. (2018). Transformasi Makna dan Fungsi Ruang di RPTRA Kalijodo dalam Pergulatan Citra Kota Jakarta. Jurnal Ruas, 16(2): 13-27.

Prakoso, S. \& Dewi, J. (2018a). Child-Friendly Integrated Public Spaces (RPTRA): Uses and Sense of Attachment. IOP Conf. Series: Earth and Environmental Science, 126(2018): 1-13

Prakoso, S. \& Dewi, J. (2018b). Rasa Kelekatan Anak Pada Ruang Publik Terpadu Ramah Anak (RPTRA). NALARs Jurnal Arsitektur, 17(1): 1-10. 
Prakoso, S. \& Dewi, J. (2018c). Panduan Rancang Taman Lingkungan Berdampak Rasa Kelekatan pada Anak: Pembelajaran dari Ruang Publik Terpadu Ramah Anak (RPTRA). Fakultas Desain UPH, Tangerang.

Purnama, M.S.S. (2017). Penerapan Konsep Ruang Publik Terpadu Ramah Anak (RPTRA) Pada Permukiman Studi Kasus: RPTRA Gandaria Selatan. Faktor Exacta, 10(4): 401-405.

Putra, R.T., Radnawati D., Syahadat R.M., Putra, P.T., \& Thoifur, D. (2018). Evaluasi Taman Jangkrik sebagai RTRA di Ciganjur, Jakarta Selatan. Prosiding Semnastek 2018, 1-8.

Rosyidin, W.F., Giyanti, S., \& Dahlia, S. (2017). Analisis Spasial Ruang Publik Terpadu Ramah Anak (RPTRA) "Puspita" Sebagai Urban Resilience di Kelurahan Pesanggrahan Jakarta Selatan. Jurnal Geografi Edukasi dan Lingkungan, 1(1): 19-26.
Suprtiyanto, Soerjoatmodjo, G.W.L., \& Prasetio, L. (2017). Gambaran Pengasuhan Anak pada Keluarga Urban yang Tinggal di Wilayah RPTRA Anggrek Bintaro, Jakarta Selatan. Jurnal Muara Ilmu Sosial, Humaniora, dan Seni, 1(1):30-41.

Sutanto, E. \& Junadi, P. (2018). Kalijodo Transformation in Establishment of Healthy Environment in Jakarta. IOP Conf. Series: Earth and Environmental Science 126(2018): 1-11.

Utami, P.K., Mugnisjah, W.Q., \& Munandar, A. (2016) Partisipasi Masyarakat Kota Berbasis Manfaat dalam Membentuk Taman Publik Ramah Anak. Jurnal Lanskap Indonesia, 8(2): 28-38

Wardiningsih, S. Syahadat, R.M., Putra, P.T., Purwati, R., \& Hasibuan, M.S.R. (2017). Perencanaan Tata Hijau Lanskap Sempadan Setu Mangga Bolong sebagai Area Konservasi Tumbuhan Bernilai Ekologis dan Budaya. NALAR's Jurnal Arsitektur, 6(2): 135-144.

Windarsih, A. (2013). Memahami Betawi dalam Konteks Cagar Budaya Condet dan Setu Babakan. Jurnal Masyakarat \& Budaya, 15(1): 177-200. 